\title{
Collection and Evaluation of Genetic Variation of Perilla Accessions in the Jeju Island
}

\author{
Su Yeon Woo ${ }^{1}$, Kyu Jin Sa ${ }^{1}$, Ju Kyong Lee ${ }^{1,2 *}$ \\ ${ }^{1}$ Division of Bio-Resource Sciences, College of Agriculture and Life Sciences, Kangwon National University, Chuncheon 24341, Korea \\ ${ }^{2}$ Bioherb Research Institute, Kangwon National University, Chuncheon 24341, Korea
}

\begin{abstract}
In order to understand the genetic variation of the cultivated and weedy types of Perilla crop in Jeju Island of Korea, this study has conducted a field expedition for collecting Perilla germplasm in 2011 and 2012, respectively. Cultivated Perilla crop was almost not cultivated throughout the island, whereas weedy types of both varieties (var.) of frutescens and crispa were often found in roadsides, around a creek, in wastelands, and in areas around a farmer's fields. The total number of collection was 94 accessions. The seed colors of cultivated var. frutescens were white and brown, while the weedy var. frutescens were gray, brown, and dark brown. The weedy var. crispa exhibited gray and dark brown seed colors. The most accessions of cultivated var. frutescens and weedy types of var. frutescens and var. crispa revealed hard seeds, except one accession of cultivated var. frutescens which had soft seeds. A total of 17 simple sequence repeat loci showed polymorphism, producing a total of 149 alleles among the 85 Perilla accessions collected from Jeju Island. The average gene diversity for accessions of cultivated var. frutescens, weedy var. frutescens, and weedy var. crispa respectively showed $0.346,0.649$, and 0.463 . The accessions of weedy types of var. frutescens and var. crispa comparatively exhibited higher genetic diversity than those of cultivated var. frutescens. The accessions collected would be useful for preserving the genetic diversity of this crop for further breeding programs of the Perilla crop in Korea.
\end{abstract}

Keywords Perilla frutescens, Cultivated and weedy types, Field survey, Genetic variation, Germplasm

\section{INTRODUCTION}

Perilla frutescens Britt. (Labiatae) is a self-fertilizing annual species, which is widely cultivated and distributed in the Himalayan hills, Southeast Asia, and East Asia. The species includes two varieties that are characterized on the basis of their morphology and utilization. One is $P$. frutescens var. frutescens, an oil crop, which is known as Dlggae in Korea. Another is P. frutescens var. crispa, a Chinese medicine or vegetable crop, and called as Cha-jo-ki in Korea (Lee and Ohnishi 2001). In addition to those two cultigens, weedy plants of both var. frutescens and var. crispa were reported by Nitta and Ohnishi (1999) and Lee and Ohnishi $(2001,2003)$. They are commonly found in such habitats as roadsides, wastelands, abandoned fields, and the marginal lands around the farmers' fields in East Asia (Lee and Ohnishi 2001; Nitta et al. 2003).
In Korea, cultivated var. frutescens has been one of the most important oil crops since ancient times. According to a report by Choi (1984), Perilla seed oil has been used not only for edible oil but also for industrial oil. It has been used for lamp oil, waterproofing papers for umbrella and other rain-gear, and lacquer for wooden furniture, wooden vessels, and living households. Also, its seeds, like sesame seeds for the seasoning of flavoring agents, are used as folk medicine for illnesses as inveterate gastritis, cough, and restorative (Lee 2001). Moreover, in Korea, var. frutescens is used not only as an oil crop for its seeds but also as a vegetable crop for its leaves to become one of the most important crops. However, germplasm collections and classifications have not been carried out systematically and the breeding of this crop is far behind other major crops in Korea.

The success of breeding or the genetic conservation

Received September 21, 2015; Revised October 30, 2015; Accepted October 30, 2015; Published February 28, 2016

*Corresponding author Ju Kyong Lee, jukyonglee@kangwon.ac.kr, Tel: +82-33-250-6415, Fax: +82-33-259-5558 
programs is dependent on the understanding of the amount and distribution of the genetic variation present in genepool. In order to clarify the cultivation, utilization, and distribution of Perilla species in Korea, this study conducted a field survey throughout the Jeju Island in 2011 and 2012. In Korea, Jeju Island is located in the southernmost portion of South Korea and is also the largest island in the land, coming into existence 700 to 1,200 thousand years ago when lava spewed from a sub-sea volcano and surfaced above the waters, which led to a mild oceanic climate throughout the year with the smallest annual temperature range.

Recently, molecular techniques of polymerase chain reaction (PCR)-based DNA markers such as Random Amplified Polymorphic DNA, Amplified Fragment Length Polymorphisms (AFLPs), and simple sequence repeats (SSRs) have provided useful information regarding genetic diversity and relationships in many crops (Ajmone-Marsan et al. 1998; Senior et al. 1998; Nitta and Ohnishi 1999; Prasad et al. 2000; Lee and Ohnishi 2003; Xia et al. 2005; Sa et al. 2010). Among the many kinds of DNA-based molecular markers, particularly SSRs or SSRs are very abundant in eukaryotic genomes and hypervariable in the repeat units between plants in a given plant population, and the preferred choice for genetic studies because they are highly reproducible, polymorphic, codominant, and abundant in plant genomes (Powell et al. 1996; Park et al. 2009). In the previous study, Perilla SSRs were developed by Kwon et al. (2005) and Park et al. (2008), respectively, and also used to analyze the genetic diversity and genetic relationships in Perilla germplasm from Korea, East Asian and other countries (Lee et al. 2007; Lee and Kim 2007; Park et al. 2008; Sa et al. 2015).

Moreover, understanding genetic diversity and genetic relationships in Perilla crop and their weedy types is essential for the long-term success of breeding programs and maximizes the use of the Perilla germplasm resources in Korea. Therefore, in this study, the result of the field survey and the analysis of genetic variation using SSR and morphological markers for understanding the genetic diversity and conservation condition of Perilla crop and their weedy types in Jeju Island of Korea are reported.

\section{MATERIALS AND METHODS}

\section{Collection for Perilla crop and their weedy types}

A field survey for the cultivation of Perilla crop and their weedy types in Jeju Island of Korea was respectively conducted from October 24 to October 26 in 2011 and from October 31 to November 3 in 2012 (Fig. 1, Table 1). More than 30 villages were visited and numerous farmers were interviewed about their cultivation and utilization of Perilla crop. The natural distribution of weedy types of Perilla species in farmers' fields, roadsides, wastelands, abandoned fields, and the areas around the farmhouses was also searched. In this study, the Perilla samples were tentatively classified into cultivated or weedy type according to the morphological characters and the cultivation conditions where they were collected (cultivated or not by farmers) as based on the previous report by Lee and Ohnishi (2001) and Lee et al. (2002).

\section{Morphological characteristics analysis}

To assess the morphological variations in Perilla crop and their weedy types, five individuals of each accession were grown in a field at the Agriculture and Life Sciences, Kangwon National University, Chuncheon, Gangwon Province. Approximately 10 seeds of each accession were sown in a nursery bed in early May and maintained in a glass house for a month. Five seedlings of each accession

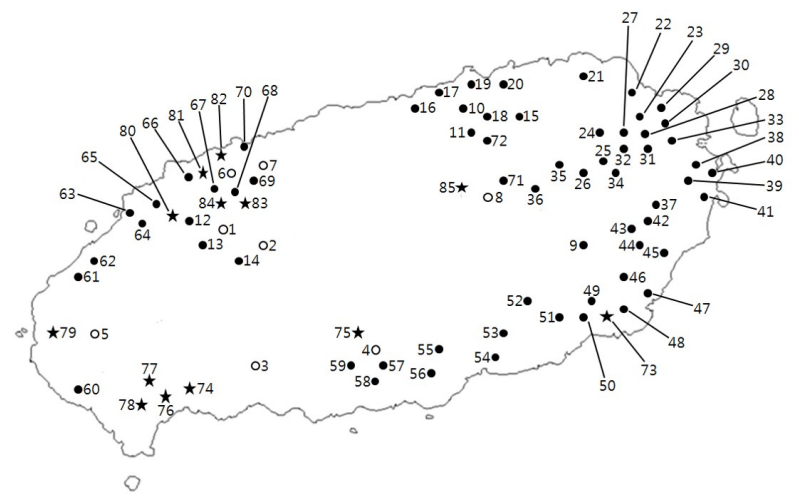

Fig. 1. Routes of the field survey and collection sites for Perilla crop and their weedy types in Jeju Island. $\bigcirc$ : accession of cultivated type of var. frutescens; -: accession of weedy type of var. frutescens; $\star$ : accession of weedy type of var. crispa. 
Table 1. Collection sites of Perilla samples in Jeju-do, Republic of Korea.

\begin{tabular}{|c|c|c|c|c|}
\hline $\begin{array}{l}\text { Accession } \\
\text { no. }\end{array}$ & $\begin{array}{l}\text { Collection } \\
\text { date }\end{array}$ & $\begin{array}{c}\text { Source of material } \\
\text { (village, town, or city) }\end{array}$ & Type & Code no. ${ }^{\text {z) }}$ \\
\hline PF11-106 & $2011 / 10 / 24$ & Seongeup-ri, Pyoseon-myeon, Seogwipo & Weedy var. frutescens & 7 \\
\hline PF11-107 & $2011 / 10 / 24$ & Doryeon-1 dong, Jeju & Weedy var. frutescens & 8 \\
\hline PF11-108 & $2011 / 10 / 24$ & Doryeon-1 dong, Jeju & Weedy var. frutescens & 9 \\
\hline PF11-109 & $2011 / 10 / 25$ & Bongseong-ri, Aewol-eup, Jeju & Weedy var. frutescens & 10 \\
\hline PF11-110 & $2011 / 10 / 25$ & Bongseong-ri, Aewol-eup, Jeju & Weedy var. frutescens & 11 \\
\hline PF11-111 & $2011 / 10 / 25$ & Bongseong-ri, Aewol-eup, Jeju & Weedy var. frutescens & 12 \\
\hline PF11-112 & $2011 / 10 / 26$ & Seonhul-ri, Jocheon-eup, Jeju & Weedy var. frutescens & 13 \\
\hline PF11-113 & $2011 / 10 / 26$ & Seonhul-ri, Jocheon-eup, Jeju & Weedy var. frutescens & \\
\hline PF11-114 & $2011 / 10 / 26$ & Bongseong-ri, Aewol-eup, Jeju & Weedy var. crispa & 82 \\
\hline PF11-115 & $2011 / 10 / 26$ & Bongseong-ri, Aewol-eup, Jeju & Cultivated var. frutescens & 1 \\
\hline PF12-019 & $2012 / 10 / 31$ & Samyang-dong, Jeju & Weedy var. frutescens & 14 \\
\hline PF12-020 & $2012 / 10 / 31$ & Samyang-dong, Jeju & Weedy var. frutescens & \\
\hline PF12-021 & $2012 / 10 / 31$ & Samyang-dong, Jeju & Weedy var. frutescens & 15 \\
\hline PF12-022 & $2012 / 10 / 31$ & Jochen-ri, Jochen-eup, Jeju & Weedy var. frutescens & 16 \\
\hline PF12-023 & $2012 / 10 / 31$ & Jochen-ri, Jochen-eup, Jeju & Weedy var. frutescens & 17 \\
\hline PF12-024 & $2012 / 10 / 31$ & Jochen-ri, Jochen-eup, Jeju & Weedy var. frutescens & 18 \\
\hline PF12-025 & $2012 / 10 / 31$ & Woljeong-ri, Gujwa-eup, Jeju & Weedy var. frutescens & 19 \\
\hline PF12-026 & $2012 / 10 / 31$ & Sehwa-ri, Gujwa-eup, Jeju & Weedy var. frutescens & 20 \\
\hline PF12-027 & $2012 / 10 / 31$ & Sehwa-ri, Gujwa-eup, Jeju & Weedy var. frutescens & 21 \\
\hline PF12-028 & $2012 / 10 / 31$ & Sehwa-ri, Gujwa-eup, Jeju & Weedy var. frutescens & 22 \\
\hline PF12-029 & $2012 / 10 / 31$ & Sehwa-ri, Gujwa-eup, Jeju & Weedy var. frutescens & 23 \\
\hline PF12-030 & $2012 / 10 / 31$ & Sehwa-ri, Gujwa-eup, Jeju & Weedy var. frutescens & 24 \\
\hline PF12-031 & $2012 / 10 / 31$ & Sehwa-ri, Gujwa-eup, Jeju & Weedy var. frutescens & 25 \\
\hline PF12-032 & $2012 / 10 / 31$ & Sangdo-ri, Gujwa-eup, Jeju & Weedy var. frutescens & 26 \\
\hline PF12-033 & $2012 / 10 / 31$ & Sangdo-ri, Gujwa-eup, Jeju & Weedy var. frutescens & 27 \\
\hline PF12-034 & $2012 / 10 / 31$ & Sangdo-ri, Gujwa-eup, Jeju & Weedy var. frutescens & 28 \\
\hline PF12-035 & $2012 / 10 / 31$ & Sangdo-ri, Gujwa-eup, Jeju & Weedy var. frutescens & \\
\hline PF12-036 & $2012 / 10 / 31$ & Sangdo-ri, Gujwa-eup, Jeju & Weedy var. frutescens & 29 \\
\hline PF12-037 & $2012 / 10 / 31$ & Sangdo-ri, Gujwa-eup, Jeju & Weedy var. frutescens & 30 \\
\hline PF12-038 & $2012 / 10 / 31$ & Sangdo-ri, Gujwa-eup, Jeju & Weedy var. frutescens & 31 \\
\hline PF12-039 & $2012 / 10 / 31$ & Sangdo-ri, Gujwa-eup, Jeju & Weedy var. frutescens & 32 \\
\hline PF12-040 & $2012 / 10 / 31$ & Songdang-ri, Gujwa-eup, Jeju & Weedy var. frutescens & \\
\hline PF12-041 & $2012 / 10 / 31$ & Songdang-ri, Gujwa-eup, Jeju & Weedy var. frutescens & 33 \\
\hline PF12-042 & $2012 / 10 / 31$ & Songdang-ri, Gujwa-eup, Jeju & Weedy var. frutescens & 34 \\
\hline PF12-043 & $2012 / 10 / 31$ & Susan-ri, Seongsan-eup, Seogwipo & Weedy var. frutescens & 35 \\
\hline PF12-044 & 2012/11/01 & Siheung-ri, Seongsan-eup, Seogwipo & Weedy var. frutescens & \\
\hline PF12-045 & 2012/11/01 & Siheung-ri, Seongsan-eup, Seogwipo & Weedy var. frutescens & 36 \\
\hline PF12-046 & 2012/11/01 & Siheung-ri, Seongsan-eup, Seogwipo & Weedy var. frutescens & 37 \\
\hline PF12-047 & 2012/11/01 & Siheung-ri, Seongsan-eup, Seogwipo & Weedy var. frutescens & 38 \\
\hline PF12-048 & $2012 / 11 / 01$ & Sinyang-ri, Seongsan-eup, Seogwipo & Weedy var. crispa & 83 \\
\hline PF12-049 & $2012 / 11 / 01$ & Nansan-ri, Seongsan-eup, Seogwipo & Weedy var. frutescens & 39 \\
\hline PF12-050 & $2012 / 11 / 01$ & Nansan-ri, Seongsan-eup, Seogwipo & Weedy var. frutescens & 40 \\
\hline PF12-051 & 2012/11/01 & Nansan-ri, Seongsan-eup, Seogwipo & Weedy var. frutescens & \\
\hline PF12-052 & $2012 / 11 / 01$ & Samdal-ri, Seongsan-eup, Seogwipo & Weedy var. frutescens & 41 \\
\hline PF12-053 & 2012/11/01 & Samdal-ri, Seongsan-eup, Seogwipo & Weedy var. frutescens & 42 \\
\hline PF12-054 & $2012 / 11 / 01$ & Seongeup-ri, Pyoseon-myeon, Seogwipo & Weedy var. frutescens & \\
\hline PF12-055 & $2012 / 11 / 01$ & Hacheon-ri, Pyoseon-myeon, Seogwipo & Weedy var. frutescens & 43 \\
\hline
\end{tabular}


Table 1. Continued.

\begin{tabular}{|c|c|c|c|c|}
\hline $\begin{array}{l}\text { Accession } \\
\text { no. }\end{array}$ & $\begin{array}{l}\text { Collection } \\
\text { date }\end{array}$ & $\begin{array}{c}\text { Source of material } \\
\text { (Village, town, or city) }\end{array}$ & Type & Code no. ${ }^{\text {z) }}$ \\
\hline PF12-056 & 2012/11/01 & Hacheon-ri, Pyoseon-myeon, Seogwipo & Weedy var. frutescens & 44 \\
\hline PF12-057 & $2012 / 11 / 01$ & Hacheon-ri, Pyoseon-myeon, Seogwipo & Weedy var. frutescens & 45 \\
\hline PF12-058 & 2012/11/01 & Pyoseon-ri, Pyoseon-myeon, Seogwipo & Weedy var. frutescens & 46 \\
\hline PF12-059 & $2012 / 11 / 01$ & Sehwa-ri, Pyoseon-myeon, Seogwipo & Weedy var. frutescens & 47 \\
\hline PF12-060 & 2012/11/01 & Singeung-ri, Namwon-eup, Seogwipo & Weedy var. frutescens & \\
\hline PF12-061 & 2012/11/01 & Singeung-ri, Namwon-eup, Seogwipo & Weedy var. frutescens & 48 \\
\hline PF12-062 & $2012 / 11 / 01$ & Singeung-ri, Namwon-eup, Seogwipo & Weedy var. frutescens & 49 \\
\hline PF12-063 & $2012 / 11 / 01$ & Hannam-ri, Namwon-eup, Seogwipo & Weedy var. frutescens & 50 \\
\hline PF12-064 & 2012/11/01 & Wimi-ri, Namwon-eup, Seogwipo & Weedy var. frutescens & 51 \\
\hline PF12-065 & $2012 / 11 / 01$ & Wimi-ri, Namwon-eup, Seogwipo & Weedy var. frutescens & 52 \\
\hline PF12-066 & 2012/11/01 & Harye-ri, Namwon-eup, Seogwipo & Weedy var. frutescens & 53 \\
\hline PF12-067 & 2012/11/01 & Harye-ri, Namwon-eup, Seogwipo & Weedy var. frutescens & \\
\hline PF12-068 & 2012/11/01 & Harye-ri, Namwon-eup, Seogwipo & Weedy var. frutescens & 54 \\
\hline PF12-069 & 2012/11/01 & Hwasun-ri, Andeok-myeon, Seogwipo & Weedy var. frutescens & 55 \\
\hline PF12-070 & 2012/11/01 & Sangye-dong, Seogwipo & Cultivated var. frutescens & 2 \\
\hline PF12-071 & $2012 / 11 / 02$ & Seohong-dong, Seogwipo & Cultivated var. frutescens & 3 \\
\hline PF12-072 & $2012 / 11 / 02$ & Seohong-dong, Seogwipo & Weedy var. frutescens & 56 \\
\hline PF12-073 & $2012 / 11 / 02$ & Seohong-dong, Seogwipo & Weedy var. frutescens & 57 \\
\hline PF12-074 & $2012 / 11 / 02$ & Seohong-dong, Seogwipo & Weedy var. frutescens & 58 \\
\hline PF12-075 & $2012 / 11 / 02$ & Seohong-dong, Seogwipo & Weedy var. frutescens & 59 \\
\hline PF12-076 & $2012 / 11 / 02$ & Deoksu-ri, Andeok-myeon, Seogwipo & Weedy var. frutescens & 60 \\
\hline PF12-077 & 2012/11/02 & Deoksu-ri, Andeok-myeon, Seogwipo & Weedy var. frutescens & 61 \\
\hline PF12-078 & $2012 / 11 / 02$ & Deoksu-ri, Andeok-myeon, Seogwipo & Weedy var. frutescens & 62 \\
\hline PF12-079 & $2012 / 11 / 02$ & Yeongrak-ri, Daejeong-eup, Seogwipo & Weedy var. frutescens & 63 \\
\hline PF12-080 & 2012/11/02 & Gosan-ri, Hangyeong-myeon, Jesu & Cultivated var. frutescens & 4 \\
\hline PF12-081 & $2012 / 11 / 02$ & Dumo-ri, Hangyeong-myeon, Jesu & Weedy var. frutescens & 64 \\
\hline PF12-082 & $2012 / 11 / 02$ & Wollyeong-ri, Hanllim-eup, Jesu & Weedy var. frutescens & 65 \\
\hline PF12-083 & $2012 / 11 / 02$ & Geumneung-ri, Hanllim-eup, Jesu & Weedy var. frutescens & 66 \\
\hline PF12-084 & $2012 / 11 / 02$ & Gwideok-ri, Hanllim-eup, Jesu & Weedy var. frutescens & 67 \\
\hline PF12-085 & $2012 / 11 / 02$ & Gwideok-ri, Hanllim-eup, Jesu & Weedy var. frutescens & 68 \\
\hline PF12-086 & $2012 / 11 / 02$ & Bongseong-ri, Aewol-eup, Jesu & Weedy var. frutescens & 69 \\
\hline PF12-087 & 2012/11/02 & Gwakji-ri, Aewol-eup, Jesu & Weedy var. frutescens & 70 \\
\hline PF12-088 & $2012 / 11 / 02$ & Sangga-ri, Aewol-eup, Jesu & Weedy var. frutescens & 71 \\
\hline PF12-089 & $2012 / 11 / 02$ & Haga-ri, Aewol-eup, Jesu & Weedy var. frutescens & 72 \\
\hline PF12-090 & $2012 / 11 / 02$ & Susan-ri, Aewol-eup, Jesu & Weedy var. frutescens & 73 \\
\hline PF12-091 & $2012 / 11 / 02$ & Eomjang-ro, Aewol-eup, Jesu & Cultivated var. frutescens & 5 \\
\hline PF12-092 & $2012 / 11 / 02$ & Jangjeon-ri, Aewol-eup, Jesu & Weedy var. frutescens & 74 \\
\hline PF12-093 & $2012 / 11 / 02$ & Jangjeon-ri, Aewol-eup, Jesu & Weedy var. frutescens & 75 \\
\hline PF12-094 & $2012 / 11 / 02$ & Jangjeon-ri, Aewol-eup, Jesu & Weedy var. frutescens & 76 \\
\hline PF12-095 & $2012 / 11 / 02$ & Jangjeon-ri, Aewol-eup, Jesu & Weedy var. frutescens & 77 \\
\hline PF12-096 & $2012 / 11 / 02$ & Jangjeon-ri, Aewol-eup, Jesu & Weedy var. frutescens & 78 \\
\hline PF12-097 & 2012/11/02 & Hagwi-ri, Aewol-eup, Jesu & Cultivated var. frutescens & 6 \\
\hline PF12-098 & $2012 / 11 / 02$ & Hagwi-ri, Aewol-eup, Jesu & Weedy var. frutescens & 79 \\
\hline PF12-099 & $2012 / 11 / 03$ & Gyorae-ri, Jocheon-eup, Jesu & Weedy var. crispa & 84 \\
\hline PF12-100 & $2012 / 11 / 03$ & Gyorae-ri, Jocheon-eup, Jesu & Weedy var. crispa & 85 \\
\hline PF12-101 & $2012 / 11 / 03$ & Gyorae-ri, Jocheon-eup, Jesu & Weedy var. frutescens & 80 \\
\hline PF12-102 & 2012/11/03 & Waheul-ri, Jocheon-eup, Jesu & Weedy var. frutescens & 81 \\
\hline
\end{tabular}

z) This mark indicated the accessions used for morphological and simple sequence repeat analysis. 
were then transplanted into the field in early June. In this study, four quantitative and nine qualitative characters were examined. Such were reportedly useful for the discrimination between Perilla crop and their weedy types (Lee and Ohnishi 2001). The plants were evaluated at the appropriate growth stages for each accession as described in detail in Table 2.

\section{SSR analysis and silver-staining}

SSR amplifications were conducted in a total volume of $20 \mu \mathrm{l}$ consisting of $20 \mathrm{ng}$ genomic DNA, $1 \times$ PCR buffer, 0.5 $\mu \mathrm{M}$ of forward and reverse primers, $0.2 \mathrm{mM}$ dNTPs, and 1 unit of Taq polymerase (Biotools, Madrid, Spain). The PCR profile consisted of an initial denaturation at $95^{\circ} \mathrm{C}$ for 3 minutes, followed by 36 cycles of $95^{\circ} \mathrm{C}$ for 30 seconds, $55^{\circ} \mathrm{C}$ for 30 seconds, and $72^{\circ} \mathrm{C}$ for 1 minute 30 seconds, with a final extension step of 5 minutes at $72^{\circ} \mathrm{C}$. After PCR, $5 \mu \mathrm{l}$ of the final products were mixed with $10 \mu$ of electrophoresis loading buffer (98\% formamide, $0.02 \%$ bromophenol blue, $0.02 \%$ Xylene $\mathrm{C}$, and $5 \mathrm{mM} \mathrm{NaOH})$. After denaturing and immediate cooling, $2 \mu \mathrm{l}$ from each sample was loaded onto $6 \%$ denaturing (7.5 M urea) acrylamide- bisacrylamide gel $(19: 1)$ in $1 \times$ Tris-borate-EDTA (TBE) buffer and then electrophoresed at $1,800 \mathrm{~V}$ and $60 \mathrm{~W}$ for 130 minutes. The separated fragments were then visualized using a silver staining kit (Promega, Madison, WI, USA).

\section{Data analysis}

Fragments amplified by SSR primers were scored as present (1) or absent (0), and the genetic diversity was then calculated for each group of accessions according to the formula developed by Nei (1973): Genetic diversity $=1-$ $\sum P_{i}^{2}$, where $P_{i}$ is the frequency of the $\mathrm{i}^{\text {th }} \mathrm{SSR}$ allele present in the group of accessions. Anderson et al. (1993) measured genetic diversity in terms of polymorphic information content (PIC). The genetic similarities (GS) were calculated for each pair of accessions using the Dice similarity index (Dice 1945). The similarity matrix was used to construct an un-weighted pair group methods using arithmetic averages algorithm (UPGMA) dendrogram with the help of SAHN-Clustering by NTSYS-pc.V.2.1 (Rohlf 2000). In addition, a principal coordinate (PCO) analysis based on the GS matrices was carried out to estimate relationships among accessions of Perilla crop and their weedy types using the principal component analysis programs of the NTSYS-pc software package (Rohlf 2000).

\section{RESULTS}

\section{Collection for cultivated and weedy types of Perilla crop in Jeju Island}

Table 1 summarizes the result of the field survey in Jeju Island of Korea. The villages or towns visited are plotted on

Table 2. Characters used in the morphological analysis of Perilla crop.

\begin{tabular}{clll}
\hline \hline Abbreviation $^{\mathrm{z})}$ & \multicolumn{1}{c}{ Character } & When/How measured & \multicolumn{1}{c}{ Category } \\
\hline QN1 & Days from seeding to flowering & At flowering stage & Day \\
QN2 & Plant height & At flowering stage & $\mathrm{cm}$ \\
QN3 & Number of internodes & At flowering stage & Number \\
QN4 & Length of the largest inflorescence & After harvest & $\mathrm{cm}$ \\
QL1 & Seed color & After harvest & White-1, gray-2, brown-3, dark brown-4 \\
QL2 & Seed hardness & After harvest & Soft-1, hard-2 \\
QL3 & Color of leaf surface & At flowering stage & Green-1, green/purple-2, purple-3, deep purple-4 \\
QL4 & Color of reverse side of leaf & At flowering stage & Green-1, green/purple-2, purple-3, deep purple-4 \\
QL5 & Color of stem & At flowering stage & Green-1, green/purple-2, purple-3 \\
QL6 & Degree of pubescence & At flowering stage & Slightly purbescent-1, purbescent-2, heavily purbescent-3 \\
QL7 & Color of flower & At flowering stage & White-1, white/purple-2, purple-3 \\
QL8 & Shape of leaf & At flowering stage & Wrinkle-1, none wrinkle-2 \\
QL9 & Seed size & After harvest & Large ( $>2$ mm)-1, small $(<2$ mm)-2 \\
\hline
\end{tabular}

${ }^{\mathrm{z})} \mathrm{QN}$ : quantitative, QL: qualitative. 
Table 3. Morphological characterization of cultivated and weedy types of Perilla crop in Jeju Island of Korea.

\begin{tabular}{|c|c|c|c|}
\hline \multirow{2}{*}{ Morphological character ${ }^{2)}$} & \multicolumn{2}{|c|}{ Var. frutescens } & \multirow{2}{*}{$\begin{array}{c}\text { Var. crispa } \\
\text { Weedy type }\end{array}$} \\
\hline & Cultivated type & Weedy type & \\
\hline QN1 (days from seeding to flowering) & $\begin{array}{l}137.8 \pm 6.7 \\
(126.0-143.0)\end{array}$ & $\begin{array}{l}134.6 \pm 2.7 \\
(129.0-143.0)\end{array}$ & $\begin{array}{l}137.8 \pm 3.3 \\
(133.0-140.0)\end{array}$ \\
\hline QN2 (plant height) & $\begin{array}{l}151.7 \pm 14.2 \\
(136.0-177.0)\end{array}$ & $\begin{array}{l}163.1 \pm 15.6 \\
(119.0-195.5)\end{array}$ & $\begin{array}{l}159.3 \pm 8.3 \\
(148.0-168.0)\end{array}$ \\
\hline QN3 (number of internodes) & $\begin{array}{l}15.8 \pm 1.3 \\
(14.0-18.0)\end{array}$ & $\begin{array}{l}17.1 \pm 1.3 \\
(13.0-20.0)\end{array}$ & $\begin{array}{l}16.3 \pm 1.0 \\
(15.0-17.0)\end{array}$ \\
\hline QN4 (length of the largest inflorescence) & $\begin{array}{l}5.7 \pm 0.5 \\
(5.0-6.0)\end{array}$ & $\begin{array}{l}9.3 \pm 2.1 \\
(5.0-15.5)\end{array}$ & $\begin{array}{l}7.3 \pm 1.3 \\
(6.0-9.0)\end{array}$ \\
\hline QL1 (seed color) & White (2), brown (4) & $\begin{array}{l}\text { Gray (1), brown (1), } \\
\text { dark brown (73) }\end{array}$ & Gray (2), dark brown (2) \\
\hline QL2 (seed hardness) & Soft (1), hard (5) & Hard (75) & Hard (4) \\
\hline QL3 (color of surface leaf) & Green (6) & Green (73), pale purple (2) & $\begin{array}{l}\text { Green (2), purple (1), } \\
\text { deep purple (1) }\end{array}$ \\
\hline QL4 (color of reverse leaf) & Green (6) & Green (69), pale purple (6) & Purple (1), deep purple (3) \\
\hline QL5 (color of stem) & Green (6) & Green $(60)$, pale purple $(15)$ & Pale purple (2), purple (2) \\
\hline QL6 (degree of pubescence) & Pubescent (6) & $\begin{array}{l}\text { Slightly pubescent (16), } \\
\text { pubescent (55), havily pubescent (4) }\end{array}$ & Slightly pubescent (4) \\
\hline QL7 (flower color) & White (6) & White (68), purple (7) & Purple (4) \\
\hline QL8 (leaf shape) & None wrinkle (6) & None wrinkle (75) & None wrinkle (3), wrinkle (1) \\
\hline QL9 (sseed size) & Large (6) & Small (75) & Small (4) \\
\hline
\end{tabular}

Values are presented as mean \pm standard deviation (range) or number only.

${ }^{\mathrm{z})} \mathrm{QN}$ : quantitative, QL: qualitative.

a map in Fig. 1 which showed that the weedy type of var. frutescens was widely distributed in Jeju Island. The accessions of weedy type of var. frutescens were commonly found in such habitats as roadsides, wastelands, and the lands around farmer's fields and farmhouses. Meanwhile, the cultivated type of var. frutescens was almost not cultivated in there. Some farmers had grown them only a little. In addition, the cultivation of var. crispa was not seen anywhere the researchers visited, and even its weedy type was infrequently found as a relict form at roadsides, around a creek, at wastelands, and at the lands around farmhouses. On the interview with the farmers, the farmers said that in Jeju Island, sesame crop was cultivated more than Perilla crop in order to produce oil, and the seeds of var. frutescens were mainly used for the seasoning of flavoring agents like sesame seeds. The weedy type of var. crispa was often used for cooking as the leaves of var. crispa for a spice in a pepper pot soup. The total number of collections was 94 accessions which constituted of 6 cultivated var. frutescens, 84 weedy types of var. frutescens, and 4 weedy types of var. crispa, respectively (Table 1). A subset of

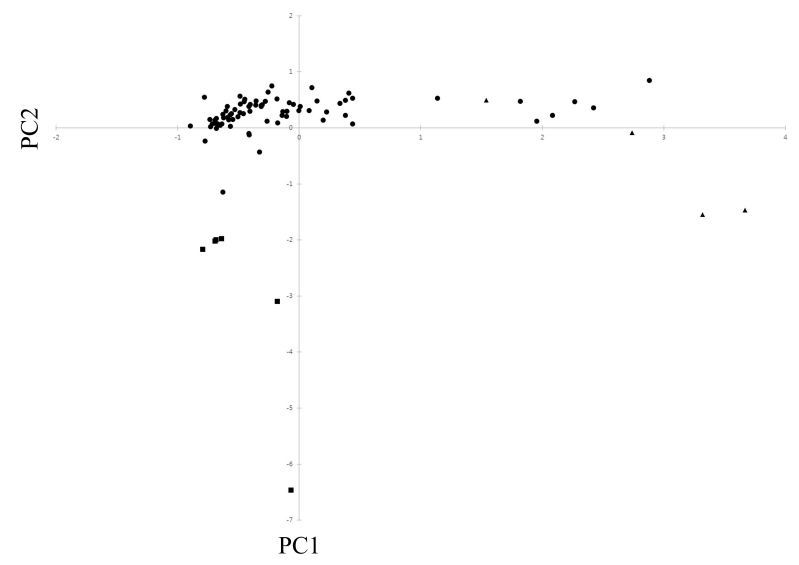

Fig. 2. Scatter diagram of 85 Perilla crop in Jeju Island based on principal component I (PC1) and II (PC2). - : cultivated type of var. frutescens; $\bullet$ : weedy type of var. frutescens; $\mathbf{\Delta}$ : weedy type of var. crispa.

each collection was deposited in the National Agrobiodiversity Center, Rural Development and Administration, Jeonju, Jeollabuk-do, Republic of Korea, for permanent seed preservation. 


\section{Morphological variation for accessions of cultivated and weedy types of Perilla crop in Jeju Island}

Table 3 shows the morphological features of these collections. The seed colors of the cultivated var. frutescens were white and brown, while the weedy type of var. frutescens showed gray, brown, and dark brown seed colors. The weedy type of var. crispa showed gray and dark brown seed colors. The most accessions of cultivated var. frutescens and weedy types of var. frutescens and var. crispa showed hard seeds, except one accession of cultivated var. frutescens which had soft seeds. The degree of leaf pubescence was variable in each type; dense in the cultivated var. frutescens, slight or dense in weedy type of var. frutescens, and slight in weedy type of var. crispa. In addition, the color of stem and leaf was variable in each type; green in the cultivated var. frutescens, green or pale purple in weedy type of var. frutescens, purple or deep purple in weedy type of var. crispa. The days from seeding to flowering did not show any difference in the cultivated var. frutescens and weedy types of var. frutescens and var. crispa. In case of plant height and plant fragrance, most

Table 4. Characteristics of the 17 simple sequence repeat loci including repeat motif, allele size range, allele numbers and gene diversity among 85 accessions of cultivated and weedy types of Perilla crop in Jeju Island.

\begin{tabular}{|c|c|c|c|c|c|c|c|}
\hline SSR loci & Primer sequence & Repeat motif & $\begin{array}{l}\text { Allele size } \\
\text { range (bp) }\end{array}$ & $\begin{array}{l}\text { No. of } \\
\text { alleles }\end{array}$ & MAF $^{z)}$ & GD & PIC \\
\hline KWPE-5 & $\begin{array}{l}\text { F - ATCTCCAAGCTTATGAATGC } \\
\text { R - CTGGTAGTGAGCCTGTTCAT }\end{array}$ & {$\left[(\mathrm{ATG})_{6}(\mathrm{GA})_{5}\right]$} & $222-250$ & 11 & 0.306 & 0.781 & 0.750 \\
\hline KWPE-19 & $\begin{array}{l}\mathrm{F} \text { - CAACCCTTCACGATCACTAT } \\
\mathrm{R} \text { - AAATAACGGCCGATTCTAC }\end{array}$ & $(\mathrm{ACG})_{7}$ & $226-249$ & 12 & 0.612 & 0.597 & 0.575 \\
\hline KWPE-25 & $\begin{array}{l}\mathrm{F} \text { - ACATTTAAGAGAGAGAGCAAG } \\
\mathrm{R} \text { - ACGAACGGGCTTCAATCTT }\end{array}$ & {$\left[(\mathrm{GT})_{8}(\mathrm{GA})_{14}\right]$} & $212-240$ & 9 & 0.306 & 0.803 & 0.777 \\
\hline KWPE-26 & $\begin{array}{l}\text { F - GAGGCAATGCTGGTACTTC } \\
\text { R - GAACGGGCTTCAATCTTC }\end{array}$ & {$\left[(\mathrm{AG})_{6}(\mathrm{AG})_{7}(\mathrm{GA})_{13}\right]$} & $240-280$ & 7 & 0.318 & 0.766 & 0.728 \\
\hline KWPE-29 & $\begin{array}{l}\text { F - AAGACAAGGAGGAAGATGC } \\
\text { R - ATAGGTGTTCGCTCTCCTGTG }\end{array}$ & $(\mathrm{GAA})_{5}$ & $217-236$ & 10 & 0.224 & 0.839 & 0.819 \\
\hline KWPE-32 & $\begin{array}{l}\mathrm{F} \text { - AGAACAACATTGTAGCTCGG } \\
\mathrm{R} \text { - ACGACCAACCAGTAGATGAT }\end{array}$ & $(\mathrm{CCT})_{4}$ & $220-228$ & 4 & 0.729 & 0.442 & 0.414 \\
\hline KWPE-39 & $\begin{array}{l}\mathrm{F} \text { - AGAACAACATTGTAGCTCGG } \\
\mathrm{R} \text { - GACGAACCAGCAAACGAC }\end{array}$ & $(\mathrm{CCT})_{4}$ & $198-230$ & 5 & 0.765 & 0.396 & 0.374 \\
\hline KWPE-48 & $\begin{array}{l}\text { F - CACCCCATCTTTTTGGAT } \\
\text { R - AGCAGGATGGTGGTGGTC }\end{array}$ & $(\mathrm{GA})_{9}$ & $214-220$ & 5 & 0.471 & 0.659 & 0.600 \\
\hline KWPE-53 & $\begin{array}{l}\text { F - ACTCACCAGAAGAGAAGAAGA } \\
\text { R - GCCACTGACCTGTTAATATCTG }\end{array}$ & $(\mathrm{CT})_{16}$ & $187-215$ & 14 & 0.200 & 0.891 & 0.880 \\
\hline KWPE-56 & $\begin{array}{l}\text { F - AAGCAGTGGACTGATTGTTT } \\
\text { R - ACAAAATCCAATTACTTTCTGC }\end{array}$ & $(\mathrm{TG})_{9}$ & $92-98$ & 5 & 0.694 & 0.479 & 0.441 \\
\hline KWPE-57 & $\begin{array}{l}\text { F - ATCACATCTCTCTCTTTCTGGA } \\
\text { R - CCAGTCACTCCATCATCTCTA }\end{array}$ & $(\mathrm{CT})_{16}$ & $150-210$ & 17 & 0.176 & 0.890 & 0.880 \\
\hline KWPE-58 & $\begin{array}{l}\text { F - AGAGAGTTACCTGCGATTTTC } \\
\text { R - CTTCAATATTCGGCCATCTT }\end{array}$ & $(\mathrm{TG})_{9}-(\mathrm{GA})_{13}$ & $161-190$ & 10 & 0.271 & 0.833 & 0.813 \\
\hline GBPFM-70 & $\begin{array}{l}\mathrm{F} \text { - CCCTCCAAATCAATATTCCA } \\
\mathrm{R} \text { - TAGCTGCCATACGAACATGA }\end{array}$ & $(\mathrm{ATTTG})_{3},(\mathrm{AC})_{5}$ & $230-240$ & 3 & 0.647 & 0.465 & 0.367 \\
\hline GBPFM-75 & $\begin{array}{l}\mathrm{F} \text { - CATAGTTCATGGCTTCCACC } \\
\mathrm{R} \text { - CCTGAGCACAGAAACAGATCA }\end{array}$ & $(\mathrm{CT})_{12}$ & $148-260$ & 7 & 0.435 & 0.709 & 0.666 \\
\hline GBPFM-91 & $\begin{array}{l}\mathrm{F} \text { - CCACTCAAATCCGCTTCTAA } \\
\mathrm{R} \text { - AATGTTGGTTGCGTTTCATT }\end{array}$ & $(\mathrm{AG})_{9}$ & $223-235$ & 4 & 0.765 & 0.375 & 0.327 \\
\hline GBPFM-111 & $\begin{array}{l}\mathrm{F} \text { - ATCATGGATGAATCGCACTT } \\
\mathrm{R} \text { - CATTCTCCAAATGTTACTCTATTT }\end{array}$ & $(\mathrm{ACACA})_{8}$ & $160-195$ & 5 & 0.729 & 0.444 & 0.418 \\
\hline GBPFM-203 & $\begin{array}{l}\text { F - GTTTTGTTGCAGCTCGATTT } \\
\text { R - TGGGTTTGGAAAGTATTGATG }\end{array}$ & {$\left[(\mathrm{GA})_{5} \mathrm{TAA}(\mathrm{AG})_{26}\right]$} & $147-225$ & 21 & 0.388 & 0.817 & 0.806 \\
\hline Average & & & & 8.8 & 0.473 & 0.658 & 0.626 \\
\hline
\end{tabular}

${ }^{2)}$ MAF: major allele frequency, GD: genetic diversity, PIC: polymorphic information content. 


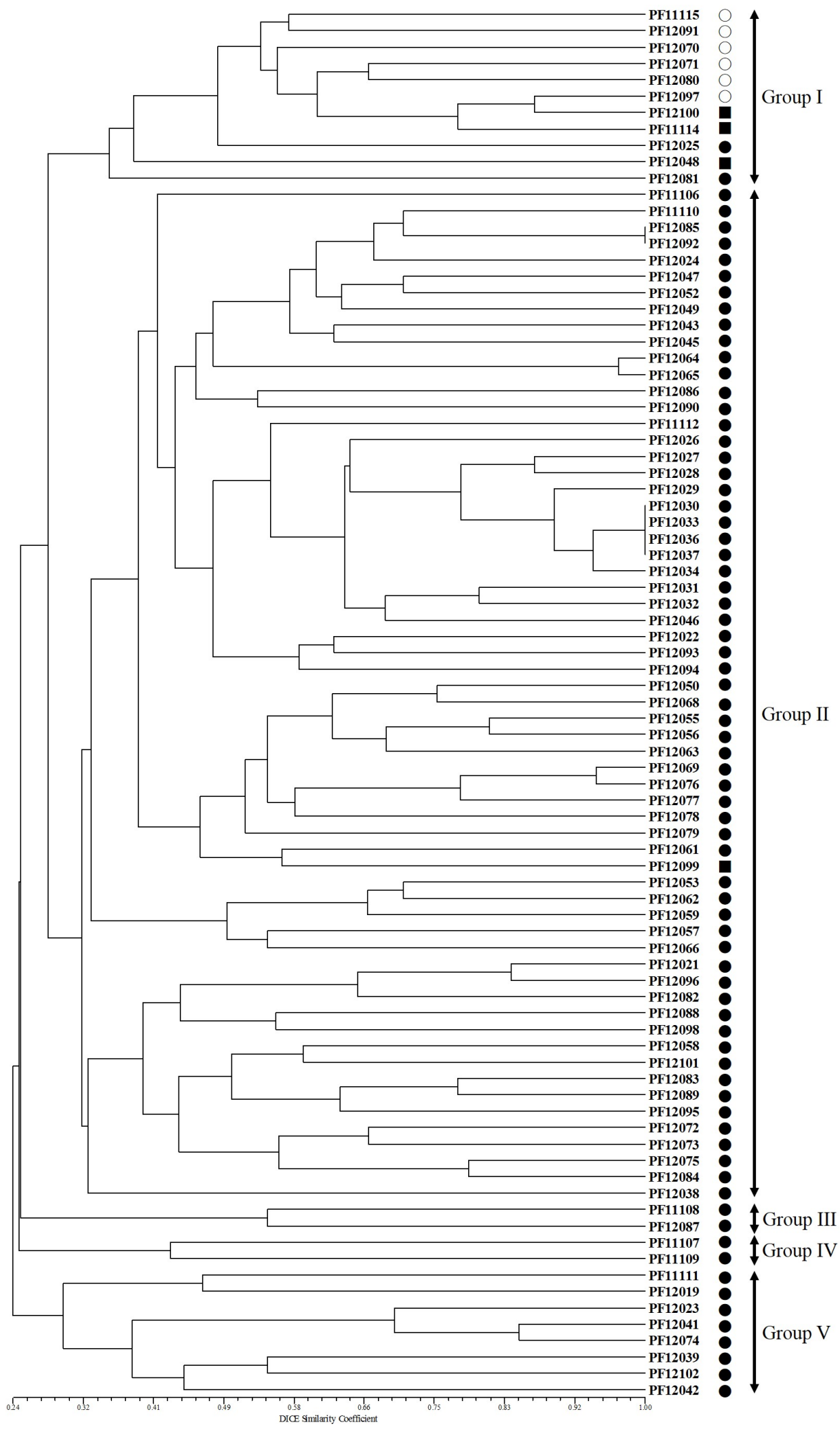

Fig. 3. Unweighted pair group method with arithmetic mean (UPGMA) dendrogram based on the simple sequence repeat marker. $\bigcirc$ : accession of cultivated var. frutescens, $\bullet$ : accession of weedy var. frutescens, $\mathbf{\bullet}$ : accession of weedy var. crispa. 
accessions of cultivated var. frutescens were $151.7 \mathrm{~cm}$ $(136-177 \mathrm{~cm})$ in average plant height, and a specific fragrance to the var. frutescens. Most accessions of weedy var. frutescens was $163.1 \mathrm{~cm}(119-195.5 \mathrm{~cm})$ in average plant height and most accessions of weedy var. crispa was $159.3 \mathrm{~cm}(148-168 \mathrm{~cm})$ in average plant height, and had weak to strong specific fragrance compared to the cultivated var. frutescens.

In the analysis of PCO, the results of PCO analysis indicated that the first and second principal components accounted for $25.7 \%$ and $21.1 \%$ of the total variation (Fig. 2 ), respectively. The scatterplot of the first two principal components is presented in Fig. 2.

\section{SSR variation and genetic relationship for accessions of cultivated weedy types of Perilla crop in Jeju Island}

The genetic variation at each SSR locus was measured in terms of the number of observed alleles, major allele frequency, gene diversity (GD), and PIC (Table 4). A total of 17 SSR loci showed polymorphism, producing a total of 149 alleles in 85 Perilla accessions selected among 94 accessions collected from Jeju Island of Korea. The loci varied in the number of observed alleles from 3 at GBPFM70 to 21 at GBPFM203, with an average of 8.8 alleles per locus. The frequency of major alleles per locus varied from 0.176 (KWPE57) to 0.765 (KWPE39, GBPFM91), with an average of 0.473 . The GD of each locus ranged from 0.375 at GBPFM91 to 0.891 at KWPE53, with an average of 0.658 . In addition, PIC values ranged from 0.327 (GBPFM91) to 0.880 (KWPE53, KWPE57), with an average of 0.626 (Table 4).

The phylogenetic tree constructed using UPGMA revealed that the 85 accessions cluster into five major groups with 29\% GS (Fig. 3). Group I contained 11 accessions that consisted of 6 of the cultivated types of var. frutescens, 2 of the weedy types of var. frutescens, and three of the weedy types of var. crispa. Group II contained 62 accessions, 61 of the weedy types of var. frutescens and one accession of the weedy type of var. crispa. Groups III and IV contained 2 accessions of the weedy type of var. frutescens, respectively. Group V contained eight accessions of the weedy type of var. frutescens. The clustering patterns observed in the present study indicated a not clear distinction between cultivated var. frutescens and the weedy types of var. frutescens and var. crispa. Although all accessions of cultivated var. frutescens were clearly separated in the three, most accessions of weedy types of var. frutescens and var. crispa did not form distinct groups.

\section{DISCUSSION}

Today, with the increase of meat consumption and the development of various cooking methods for fresh leaves and seeds, var. frutescens has become one of the most important vegetable and oil crops in Korea (Lee and Ohnishi 2001; Lee et al. 2002). However, according to the field survey in Jeju Island, most farmers did not cultivated Perilla crop in there, and only some farmers had grown a little. The interesting thing, however, was many accessions of the weedy type of var. frutescens in the field survey in Jeju Island were found. In there, the weedy var. frutescens was widely distributed, which was commonly found in such habitats as roadsides, creeks, wastelands, and lands around a farmer's fields and farmhouses. In most cases, plants of the weedy var. frutescens were recognized as an escaped form of var. frutescens by farmers. In general, weedy types have been reported in several crops; e.g., rice, barley, oat, and sorghum (Hancock 1992; Ladizinsky 1998). In these crops, the weedy types have been considered as either a wild ancestor of the crop or escaped form from cultivated crops. In the previous study by Lee and Ohnishi (2003) and Sa et al. (2013), it was suggested that the weedy types of Perilla crop in East Asia were the key taxon in understanding the origin of cultivated var. frutescens and var. crispa. Therefore, the accessions of weedy types of Perilla crop collected in Jeju Island were considered to be a highly valuable germplasm for genetic resource conservation and breeding research program in Korea.

In PCO analysis, most accessions of cultivated var. frutescens were clearly separated from weedy types of var. frutescens and var. crispa; that is, all accessions occupied the negative side below. Most accessions of weedy var. frutescens were situated on the negative and positive side, and all accessions of weedy var. crispa were situated on the 
positive side. Additionally, five accessions of weedy var. frutescens and two accessions of weedy var. crispa were closely positioned to each other. The scattering pattern of accessions of var. frutescens in Fig. 2 agreed with the clustering observed on the dendrogram (Fig. 3). In the PCO analysis, several accessions of the weedy types of var. frutescens and var. crispa could not be clearly discriminated from each other. These results indicate that some accessions of the weedy types of Perilla crop might be derived from hybrids between cultivated and weedy types of $P$. frutescens, as in a previous report by Nitta and Ohnishi (1999), Lee et al. (2002), Lee and Ohnishi (2003), and Sa et al. (2013).

On understanding the genetic diversity between cultivated and weedy types of Perilla crop in Jeju Island, the number of observed alleles and GD for 6 accessions of cultivated var. frutescens, 75 accessions of weedy var. frutescens, and 4 accessions of weedy var. crispa were measured (Table 5). As a result, the average number of alleles for accessions of cultivated var. frutescens, weedy var. frutescens, and weedy var. crispa showed 2.1, 8.5, and
2.4 alleles, respectively. The average of GD for accessions of cultivated var. frutescens, weedy var. frutescens, and weedy var. crispa respectively showed $0.346,0.649$, and 0.463 (Table 5). This result indicated that the accessions of weedy types of var. frutescens and var. crispa comparatively exhibited higher genetic diversity than those of cultivated var. frutescens. Although the value of genetic diversity for Perilla germplasm collected in Jeju Island was slightly lowered compared to that of Korean and Japanese Perilla germplasm (Sa et al. 2013) and East Asian and other countries' Perilla germplasm (Sa et al. 2015), the value of the genetic diversity of accessions of weedy var. frutescens collected in Jeju Island showed similarly to those of Korean and Japanese perilla germplasm (Sa et al. 2013) and East Asian and other countries' Perilla germplasm (Sa et al. 2015). This result indicated that although cultivated Perilla crop almost could not be cultivated in there, the weedy type of var. frutescens was considered to be well-made in the genetic conservation in Jeju Island.

In a previous report by Lee and Ohnishi (2001, 2003),

Table 5. Estimates of genetic diversity and allele number of 17 SSR loci among cultivated and weedy types of Perilla crop in Jeju Island.

\begin{tabular}{lccc}
\hline \hline & & Number of alleles/Genetic diversity & Weedy var. crispa \\
SSR & Weedy & $\begin{array}{c}\text { var. frutescens } \\
(\mathrm{n}=75)\end{array}$ \\
\cline { 2 - 4 } & $\begin{array}{c}\text { Cultivated var. frutescens } \\
(\mathrm{n}=6)\end{array}$ & $10 / 0.762$ & $3 / 0.625$ \\
KWPE5 & $3 / 0.500$ & $11 / 0.609$ & $1 / 0.000$ \\
KWPE19 & $3 / 0.611$ & $9 / 0.821$ & $3 / 0.625$ \\
KWPE25 & $1 / 0.000$ & $6 / 0.767$ & $3 / 0.625$ \\
KWPE26 & $3 / 0.500$ & $10 / 0.820$ & $2 / 0.375$ \\
KWPE29 & $2 / 0.444$ & $4 / 0.325$ & $3 / 0.625$ \\
KWPE32 & $2 / 0.444$ & $5 / 0.438$ & $1 / 0.000$ \\
KWPE39 & $1 / 0.000$ & $5 / 0.674$ & $2 / 0.375$ \\
KWPE48 & $2 / 0.278$ & $14 / 0.879$ & $3 / 0.625$ \\
KWPE53 & $4 / 0.722$ & $5 / 0.497$ & $2 / 0.375$ \\
KWPE56 & $2 / 0.278$ & $17 / 0.898$ & $3 / 0.625$ \\
KWPE57 & $2 / 0.444$ & $10 / 0.843$ & $3 / 0.625$ \\
KWPE58 & $2 / 0.444$ & $3 / 0.410$ & $2 / 0.375$ \\
GBPFM70 & $1 / 0.000$ & $7 / 0.686$ & $3 / 0.625$ \\
GBPFM75 & $3 / 0.611$ & $4 / 0.391$ & $2 / 0.375$ \\
GBPFM91 & $1 / 0.000$ & $5 / 0.420$ & $3 / 0.625$ \\
GBPFM111 & $1 / 0.000$ & $20 / 0.790$ & $2 / 0.375$ \\
GBPFM203 & $4 / 0.611$ & $8.5 / 0.649$ & $2.4 / 0.463$ \\
Average & $2.1 / 0.346$ & & \\
\hline
\end{tabular}

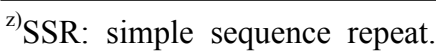


the discrimination between the cultivated var. frutescens and cultivated var. crispa was possible by the morphological characters and by the AFLP markers. However, in this study, as shown in Fig. 3, six accessions of cultivated var. frutescens and two accessions of weedy var. crispa could not be separated by SSR markers. This result indicated that the weedy type of var. crispa might be derived from hybrids between cultivated and weedy types of $P$. frutescens, as previously proposed by Nitta and Ohnishi (1999), Lee et al. (2002), Lee and Ohnishi (2003), and Sa et al. (2013). In addition, the geographic locations of the samples collected from Jeju Island have no relation with their collected position in the phylogenetic tree. This implies that the diffusion of cultivated and weedy types of Perilla crop might happen through multiple routes in Jeju Island. A similar result was obtained with AFLP analyses for Korean Perilla accessions (Lee et al. 2002). The collection of germplasm resources is important in preventing the genetic erosion of the cultivated and weedy types of Perilla crop. In this study, the field survey and genetic variation for accessions of Perilla crop and their weedy types will be helpful to future studies of the breeding program and genetic resources conservation of Perilla crop in Jeju Island of Korea.

\section{ACKNOWLEDGEMENTS}

This study was supported by the Basic Science Research Program through the National Research Foundation of Korea (NRF) funded by the Ministry of Education, Science, and Technology (2012R1A1A4A01001247) and a grant from Regional Subgenebank Support Program (PJ0115112015) of Rural Development Administration, Republic of Korea.

\section{REFERENCES}

Ajmone-Marsan P, Castiglioni P, Fusari F, Kuiper M, Motto M. 1998. Genetic diversity and its relationship to hybrid performance in maize as revealed by RFLP and AFLP markers. Theor. Appl. Genet. 96: 219-227.
Anderson JA, Churchill GA, Autrique JE, Tanksley SD, Sorrells ME. 1993. Optimizing parental selection for genetic linkage maps. Genome 36: 181-186.

Choi YJ. 1984. Deulkkae (Perilla frutescens var. frutescens): story of folk custom in Korea. New Hortic. 26: 52-53.

Dice LR. 1945. Measures of the amount of ecologic association between species. Ecology 26: 297-302.

Hancock JF. 1992. Plant evolution and the origin of crop species. Prentice Hall, Englewood Cliffs, NJ.

Kwon SJ, Lee JK, Kim NS, Yu JW, Dixit A, Cho EG, et al. 2005. Isolation and characterization of microsatellite markers in Perilla frutescens Britt. Mol. Ecol. Notes 5: 455-457.

Ladizinsky G. 1998. Plant evolution under domestication. Chapman \& Hall Published, Amsterdam.

Lee JK. 2001. Genetic differentiation of Perilla crops and their weedy types in East Asia revealed by morphological and AFLP analyses [PhD thesis]. Kyoto, Kyoto University.

Lee JK, Ohnishi O. 2001. Geographic differentiation of morphological characters among Perilla crops and their weedy types in East Asia. Breed. Sci. 51: 247-255.

Lee JK, Nitta M, Kim NS, Park CH, Yoon KM, Shin YB, et al. 2002. Genetic diversity of Perilla and related weedy types in Korea determined by AFLP analyses. Crop Sci. 42: 2161-2166.

Lee JK, Ohnishi O. 2003. Genetic relationships among cultivated types of Perilla frutescens and their weedy types in East Asia revealed by AFLP markers. Genet. Resour. Crop Evol. 50: 65-74.

Lee JK, Kim NS. 2007. Genetic diversity and relationships of cultivated and weedy types of Perilla frutescens collected from East Asia revealed by microsatellite markers. Korean J. Breed. Sci. 39: 491-499.

Lee JK, Kwon SJ, Park BJ, Kim MJ, Park YJ, Ma KH, et al. 2007. Analysis of genetic diversity and relationships of cultivated and weedy types of Perilla frutescens collected from Korea by using microsatellite markers. Korean J. Genet. 29: 81-89.

Nei M. 1973. Analysis of gene diversity in subdivided populations. Proc. Natl. Acad. Sci. U.S.A. 70: 3321-3323.

Nitta M, Ohnishi O. 1999. Genetic relationships among two Perilla crops, shiso and egoma, and the weedy type revealed by RAPD markers. Genes Genet. Syst. 74: 43-48.

Nitta M, Lee JK, Ohnishi O. 2003. Asian Perilla crops and 
their weedy forms: their cultivation, utilization and genetic relationships. Econ. Bot. 57: 245-253.

Park YJ, Dixit A, Ma KH, Lee JK, Lee MH, Chung CS, et al. 2008. Evaluation of genetic diversity and relationships within an on-farm collection of Perilla frutescens (L.) Britt. using microsatellite markers. Genet. Resour. Crop Evol. 55: 523-535.

Park YJ, Lee JK, Kim NS. 2009. Simple sequence repeat polymorphisms (SSRPs) for evaluation of molecular diversity and germplasm classification of minor crops. Molecules 14: 4546-4569.

Powell W, Morgante M, Andre C, Hanafey M, Vogel J, Tingey S, et al. 1996. The comparison of RFLP, RAPD, AFLP and SSR (microsatellite) markers for germplasm analysis. Mol. Breed. 2: 225-238.

Prasad M, Varshney RK, Roy JK, Balyan HS, Gupta PK. 2000. The use of microsatellites for detecting DNA polymorphism, genotype identification and genetic diversity in wheat. Theor. Appl. Genet. 100: 584-592.

Rohlf FJ. 2000. NTSYS- pc: Numerical taxonomy and multivariate analysis system. Version: 2.1. Exeter Software. New York, NY.

Sa KJ, Park JY, Park KJ, Lee JK. 2010. Analysis of genetic diversity and relationships among waxy maize inbred lines in Korea using SSR markers. Genes Genom. 32: 375-384

Sa KJ, Choi SH, Ueno M, Park KC, Park YJ, Ma KH, et al. 2013. Identification of genetic variations of cultivated and weedy types of Perilla species in Korea and Japan using morphological and SSR markers. Genes Genom. 35: 649-659.

Sa KJ, Choi SH, Ueno M, Lee JK. 2015. Genetic diversity and population structure in cultivated and weedy types of Perilla in East Asia and other countries as revealed by SSR markers. Hortic. Environ. Biotechnol. 56: 524-534.

Senior ML, Murphy JP, Goodman MM, Stuber C. 1998. Utility of SSRs for determining genetic similarities and relationships in maize using an agarose gel system. Crop Sci. 38: 1088-1098.

Xia XC, Reif JC, Melchinger AE, Frisch M, Hoisington DA, Beck D, et al. 2005. Genetic diversity among CIMMYT maize inbred lines investigated with SSR markers: II. Subtropical, tropical midaltitude, and highland maize inbred lines and their relationships with elite U.S. and European maize. Crop Sci. 45: 2573-2582. 